\title{
Sonographic Findings in Renal Parenchymal Diseases at Sudanese
}

\author{
Awadia Gareeballah', Moawia Gameraddin'1,2*, Hago Mustafa1, Sultan Alshabi2, \\ Fath Elerahman Alagab², Jumaa Tamboul'2, Suliman Salih ${ }^{2,3}$ \\ ${ }^{1}$ Faculty of Radiological sciences and Medical Imaging, Alzaeim Alazhari University, Khartoum, Sudan \\ ${ }^{2}$ Department of Diagnostic Radiologic Technology, Taibah University, Madinah, Saudi Arabia \\ ${ }^{3}$ National Cancer Institute, University of Gezira, Wad Medani, Sudan \\ Email: *m.bushra@yahoo.com
}

Received 18 November 2015; accepted 22 December 2015; published 25 December 2015

Copyright (C) 2015 by authors and Scientific Research Publishing Inc.

This work is licensed under the Creative Commons Attribution International License (CC BY).

http://creativecommons.org/licenses/by/4.0/

c) (i) Open Access

\begin{abstract}
Objective: The objective of this study was to assess the sonographic findings in renal parenchymal diseases using gray-scale ultrasound in order to classify these diseases. The study design was a cross-sectional one. There were 204 patients who were suspected with renal diseases. They had been scanned with ultrasound to assess the kidneys. The echogenicity, renal cortex and parenchyma, and cortico-medullary differentiation had been evaluated. Results: The study revealed that the echogenicity of renal parenchyma and cortex increased in all types of renal parenchymal diseases. The cortico-medullary differentiation was mainly disturbed in acute parenchymal disease (69.04\%), loss in chronic end-stage parenchymal disease (85\%); and there was significant difference $(p$-value $=\mathbf{0 . 0 0 0 1})$. Conclusion: Ultrasound provided useful and accurate diagnosis of renal parenchymal diseases. In this study, renal parenchymal diseases had been classified into acute, chronic and end-stage renal parenchymal diseases.
\end{abstract}

\section{Keywords}

Renal, Parenchymal, Diseases, Sonographic, Findings, Sudanese

\section{Introduction}

Ultrasonography of the kidneys has become the most routine investigation in radiology departments. The renal parenchymal diseases are most common causes of acute and chronic renal diseases which may lead to end stage renal diseases if it doesn't manage and treat properly. The treatment of these cases if it develops is very expensive and it

"Corresponding author.

How to cite this paper: Gareeballah, A., Gameraddin, M., Mustafa, H., Alshabi, S., Alagab, F.E., Tamboul, J. and Salih, S. (2015) Sonographic Findings in Renal Parenchymal Diseases at Sudanese. Open Journal of Radiology, 5, $243-249$. 
may be fatal if it is ignored. The purpose of this study is to evaluate the renal changes that associate with renal parenchymal diseases using ultrasound. Assessment of renal size, site and echogenicity can be easily determined.

Renal masses such as solid tumors can be detected and can be distinguished from renal cysts. Ultrasonography can detect nephrolithiasis and hydronephrosis. Dilated ureters can frequently be followed up to the location of the occluding concrement. The majority of renal parenchymal diseases can be classified and differentiated by ultrasonography. However, the experienced investigator can almost always distinguish normal from diseased kidneys. Detection of renal arteries is reliably possible with Color Doppler sonography [1]. Renal parenchymal diseases can be classified as uni- or bilateral diseases with small, large or normal sized kidneys. A general rule is that small kidneys depict chronic renal disease and enlarged or at least normal sized kidneys depict acute and therefore potentially reversible disease. Echogenecity is an important distinguishing sonographic parameter to evaluate renal parenchyma. Diseased kidneys in general show hyperechoich, however in the early stages echogenicity may still be normal. Increasing echogenicity is directly correlated to histopathological findings such as global sclerosis, tubular atrophy, leukocyte infiltration and the number of hyaline casts per glomerulum. Decreased echogenicity is correlated to the magnitude of interstitial edema [1].

Renal parenchymal diseases include a large number of diseases affecting the renal parenchyma and produce renal failure. Rosenfield et al. divided the diseases of renal parenchyma into those that accentuate cortical echoes but preserve or exaggerate the corticomedullary junction (type i) and those that distort the normal anatomy and obliterate the corticomedullary differentiation in either a focal or diffuse manner (type ii). In type (i), the echogenicity of renal cortex is equal to or greater than liver or spleen. Minor signs include the loss of identifiable arcuate vessels or the accentuation of corticomedullary definition. In type (ii), changes can be seen in focal disruption of normal anatomy with any mass lesion including cyst, tumor, abscesses, and heamatoma [2] [3].

Previous studies have shown that renal volume calculated at ultrasound is a more exact measurement of a functioning kidney than renal length [4] [5].

Hypertension is regarded as one of the common cause of renal parenchymal diseases. In this study, we observe that it is the second cause of renal parenchymal diseases. Most of renal diseases are associated with hypertension. This association is most prominent with glomerular diseases, including diabetic nephropathy (DN) and membranoproliferative glomerulonephritis (MPGN), in which 70\% to 80\% of patients are affected [6].

\section{Materials and Methods}

There were 204 patients above 20 years old suffering from impaired renal functions came to different hospitals in Khartoum State, Sudan, during the period from 2009 up to May 2013. The study was conducted in following hospitals; Ibn Sina, Khartoum teaching hospital, Advance Diagnostic Centre in Khatoum East and Nile Model hospital. A data collection sheet was designed to include the demographic data and clinical history of every patient. Informed consent was given to every patient. The clinical history of every patient had been reported. Pa-tients with known history of renal masses had been excluded from the study. The inclusion criteria included all-patients who had been confirmed suffering from impaired renal function. The study was approved by the local Ethics Committee of faculty of radiological sciences and medical imaging.

\subsection{Ultrasound Technique}

Using a standard B mode gray-scale ultrasound, patients were scanned using Toshiba ultrasound machine with multi-frequency curvilinear probes ( $3.5-5 \mathrm{MHz}$ ) which have variable focal zones and frequency capabilities, and AlokaProsound SSD-3500sx with two probes curvilinear probe $3.5 \mathrm{MHz}$ and linear high frequency $7.5 \mathrm{MHz}$ probe. Proper setting of the overall gain (system) gain and time gain or depth gain compensation (TGC/DGC) was adjusted to optimally visualize each kidney. Each patient was scanned twice, firstly by the researcher and then by consultant radiologists to confirm the findings and diagnosis following the international scan guidelines and protocols. Longitudinal, transverse and coronal sections were taken through the kidneys. Low tissue harmonic imaging was applied to visualize the liver, spleen and kidney in order to assess the echogenicity. Then, the echogenicity of renal cortex and parenchyma was compared with liver and spleen. When there was inter observer variation, consensus was sought.

\subsection{Statistical Analysis}

The data had been analyzed using appropriate statistical tests using SPSS version 16 . The significant test value 
was $5 \%$, all values less than $5 \%$ were regarded to be significant. Chi-square test was had been applied to find association between qualitative variables, e.g. degree of association between types of renal parenchymal diseases and corticomedullary differentiation.

\section{Results}

All patients were referred to ultrasound department for renal ultrasound examinations. It was observed that 82 patients had no clinical history (39.81\%) as shown in Table 1. Hypertension and diabetes were the most common diseases that associated with renal parenchymal disease and represent $33.01 \%$ and $7.77 \%$ respectively. It was noted that renal parenchymal diseases were mostly common at the age under 30 years old as shown in Table 2. Significant difference was existent between age and prevalence of the renal parenchymal diseases ( $p$ value $=0.0046$ ). The gender distribution of the study population revealed that acute renal parenchymal affect males and females equally ( $50 \%$ vs. $50 \%$ respectively). But in chronic and end-stage parenchymal diseases, males were more affected than females (66.67\% vs. $33.33 \%$ and $63.33 \%$ vs. $36.67 \%$ respectively) as shown in Table 3.

Table 1. Frequency distribution of patients according to clinical history.

\begin{tabular}{|c|c|c|}
\hline History & Frequency & $\%$ \\
\hline No patient history & 82 & 39.81 \\
\hline Hypertension & 68 & 33.01 \\
\hline Diabetic & 16 & 7.77 \\
\hline Diabetic and hypertensive & 10 & 4.85 \\
\hline Others & 6 & 2.91 \\
\hline Renal stone & 6 & 2.91 \\
\hline Recurrent UTI & 2 & 0.97 \\
\hline Recurrent malaria & 2 & 0.97 \\
\hline Gouty arthritis & 2 & 0.97 \\
\hline Preeclampsia & 2 & 0.97 \\
\hline Lupus erthromatosus & 2 & 0.97 \\
\hline Renal cell carcinoma & 1 & 0.48 \\
\hline Mesangiocapillary glomerulonephritis & 1 & 0.48 \\
\hline Carcinoma of U-bladder & 1 & 0.48 \\
\hline Right kidney chronic obstruction & 1 & 0.48 \\
\hline Bloody diarrhea & 1 & 0.48 \\
\hline Atherosclerosis & 1 & 0.48 \\
\hline Recurrent abortion & 1 & 0.48 \\
\hline Sickle cell anemia & 1 & 0.48 \\
\hline Total & 204 & 100 \\
\hline
\end{tabular}

Table 2. Age distribution of the study population.

\begin{tabular}{|c|c|c|c|c|c|c|}
\hline \multirow{3}{*}{ Gender } & \multicolumn{6}{|c|}{ Type of renal parenchymal diseases } \\
\hline & \multicolumn{2}{|c|}{ Acute renal parenchymal $(n=84)$} & \multicolumn{2}{|c|}{ Chronic renal parenchymal $(n=60)$} & \multicolumn{2}{|c|}{ Chronic end stage renal $(n=60)$} \\
\hline & No. & $\%$ & No. & $\%$ & No. & $\%$ \\
\hline Males & 42 & 50.00 & 40 & 66.67 & 38 & 63.33 \\
\hline Females & 42 & 50.00 & 20 & 33.33 & 22 & 36.67 \\
\hline Total & 84 & 100 & 60 & 100 & 60 & 100 \\
\hline
\end{tabular}


The results showed that workers were mostly affected with renal parenchymal diseases among the study population (27.38\% with acute renal parenchymal disease, $45 \%$ with chronic parenchymal diseases and $40 \%$ with chronic end-stage kidney diseases. Then housewives were the second group involved with renal parenchymal diseases (33.33\% with acute renal parenchymal disease, 24.34\% with chronic parenchymal disease and 21.67\% with chronic parenchymal disease) as shown in Table 4 . The echogenicity of the renal parenchyma had been categorized into four grading; hyperechoic, hypoechoic, normal and high echogenic. Increased echogenicity is an important sonographic parameter that had been changed in renal parenchymal diseases among the study population. In Table 5, the results revealed that increased echogenicity of renal parenchyma was $84.52 \%$ in patients with acute renal parenchymal diseases, $96.67 \%$ in patients with chronic renal parenchymal disease and $100 \%$ at end stage renal diseases. Results of Table 6 revealed that increased echogenicity of renal cortex was $84.52 \%$ in patients with acute renal parenchymal diseases, $96.67 \%$ in patients with chronic renal parenchymal disease and $100 \%$ at end stage renal diseases. The corticomedullary differentiatin (CMD) was changed in renal parenchymal diseases; this change depends on prolonged of pathological condition (Table 7). We used Chi-square test to find association between types of renal parenchymal diseases and CMD. Values $<0.05$ indicate there was significant association. Figure 1 and Figure 2 showed ultrasound images of the diseased kidneys.

Table 3. Ocurrence of renal parenchymal diseases in males and females of the study population.

\begin{tabular}{|c|c|c|c|c|c|c|c|}
\hline \multirow{3}{*}{ Age groups(years) } & \multicolumn{6}{|c|}{ Type of renal parenchymal diseases } & \multirow{3}{*}{$p$-value } \\
\hline & \multicolumn{2}{|c|}{$\begin{array}{l}\text { Acute renal parenchymal } \\
\qquad(n=84)\end{array}$} & \multicolumn{2}{|c|}{$\begin{array}{l}\text { Chronic renal parenchymal } \\
\qquad(n=60)\end{array}$} & \multicolumn{2}{|c|}{$\begin{array}{l}\text { Chronic end stage renal } \\
\qquad(n=60)\end{array}$} & \\
\hline & No. & $\%$ & No. & $\%$ & No. & $\%$ & \\
\hline$<20$ & 20 & 23.81 & 3 & 5.00 & 5 & 8.33 & \\
\hline $20-30$ & 20 & 23.81 & 11 & 18.33 & 13 & 21.67 & \\
\hline $31-40$ & 17 & 20.24 & 8 & 13.33 & 18 & 30.00 & \\
\hline $41-50$ & 7 & 8.33 & 6 & 10.00 & 10 & 16.67 & $0.0046^{* *}$ \\
\hline $51-60$ & 8 & 9.52 & 11 & 18.33 & 6 & 10.00 & \\
\hline$>60$ & 12 & 14.29 & 21 & 35.00 & 8 & 13.33 & \\
\hline Total & 84 & 100 & 60 & 100 & 60 & 100 & \\
\hline
\end{tabular}

Table 4. Frequency distribution of patients according to occupation and type of renal parenchymal diseases.

\begin{tabular}{ccccccc}
\hline \multirow{2}{*}{ Occupation } & \multicolumn{5}{c}{ Type of renal parenchymal diseases } \\
\cline { 2 - 7 } & \multicolumn{1}{c}{ Acute renal parenchymal $(n=84)$} & Chronic renal parenchymal $(n=60)$ & Chronic end stage renal $(n=60)$ \\
\cline { 2 - 7 } & No. & $\%$ & No. & $\%$ & No. & $\%$ \\
Worker & 23 & 27.38 & 27 & 45.00 & 24 & 40.00 \\
Employee & 21 & 25.00 & 8 & 13.33 & 6 & 10.00 \\
No occupation & 12 & 14.29 & 11 & 18.33 & 17 & 28.33 \\
Housewife & 28 & 33.33 & 14 & 24.34 & 13 & 21.67 \\
Total & 84 & 100 & 60 & 100 & 60 & 100 \\
\hline
\end{tabular}

Table 5. Grading of renal parenchymal echogenicity at renal parenchymal diseases.

\begin{tabular}{|c|c|c|c|c|c|c|}
\hline \multirow{3}{*}{$\begin{array}{l}\text { Renal parenchymal } \\
\text { echogenicity) }\end{array}$} & \multicolumn{6}{|c|}{ Type of renal parenchymal diseases } \\
\hline & \multicolumn{2}{|c|}{ Acute renal parenchymal $(n=84)$} & \multicolumn{2}{|c|}{ Chronic renal parenchymal $(n=60)$} & \multicolumn{2}{|c|}{ Chronic end stage renal $(n=60)$} \\
\hline & No. & $\%$ & No. & $\%$ & No. & $\%$ \\
\hline Hyperechoic & 71 & 84.52 & 58 & 96.67 & 60 & 100 \\
\hline Hypoechoic & 2 & 2.38 & - & - & - & - \\
\hline Normal & 9 & 10.71 & 2 & 3.33 & - & - \\
\hline Highly echogenic & 2 & 2.38 & - & - & - & - \\
\hline Total & 84 & 100 & 60 & 100 & 60 & 100 \\
\hline
\end{tabular}


Table 6. Grading of renal cortical echogenicity at renal parenchymal diseases.

\begin{tabular}{ccccccc}
\hline \multirow{2}{*}{$\begin{array}{c}\text { Renal cortical } \\
\text { echogenicity }\end{array}$} & \multicolumn{5}{c}{ Type of renal parenchymal diseases } \\
\cline { 2 - 6 } & Acute renal parenchymal $(n=84)$ & Chronic renal parenchymal $(n=60)$ & Chronic end stage renal $(n=60)$ \\
\cline { 2 - 7 } & No. & $\%$ & No. & $\%$ & No. & $\%$ \\
Hyperechoic & 71 & 84.52 & 58 & 96.67 & 60 & - \\
Hypoechoic & 2 & 2.38 & - & 3.33 & - & - \\
Normal & 9 & 10.71 & 2 & - & - & - \\
Highly echogenic & 2 & 2.38 & - & 100 & 60 & 100 \\
Total & 84 & 100 & 60 & & & - \\
\hline
\end{tabular}

Table 7. Changes of corticomedullary differentiation at renal parenchymal diseases.

\begin{tabular}{|c|c|c|c|c|c|c|c|}
\hline \multirow{3}{*}{$\begin{array}{l}\text { Corticomedullary } \\
\text { differentiation }\end{array}$} & \multicolumn{6}{|c|}{ Type of renal parenchymal diseases } & \multirow{3}{*}{$p$-value } \\
\hline & \multicolumn{2}{|c|}{$\begin{array}{c}\text { Acute renal } \\
\text { parenchymal }(n=84)\end{array}$} & \multicolumn{2}{|c|}{$\begin{array}{l}\text { Chronic renal } \\
\text { parenchymal }(n=60)\end{array}$} & \multicolumn{2}{|c|}{$\begin{array}{l}\text { Chronic end stage renal } \\
\qquad(n=60)\end{array}$} & \\
\hline & No. & $\%$ & No. & $\%$ & No. & $\%$ & \\
\hline Preserved & 12 & 14.29 & 10 & 16.67 & 1 & 1.67 & \multirow{4}{*}{0.0001} \\
\hline Lost & 14 & 16.67 & 10 & 16.67 & 51 & 85.00 & \\
\hline Disturbed & 58 & 69.04 & 40 & 66.66 & 8 & 13.33 & \\
\hline Total & 84 & 100 & 60 & 100 & 60 & 100 & \\
\hline
\end{tabular}

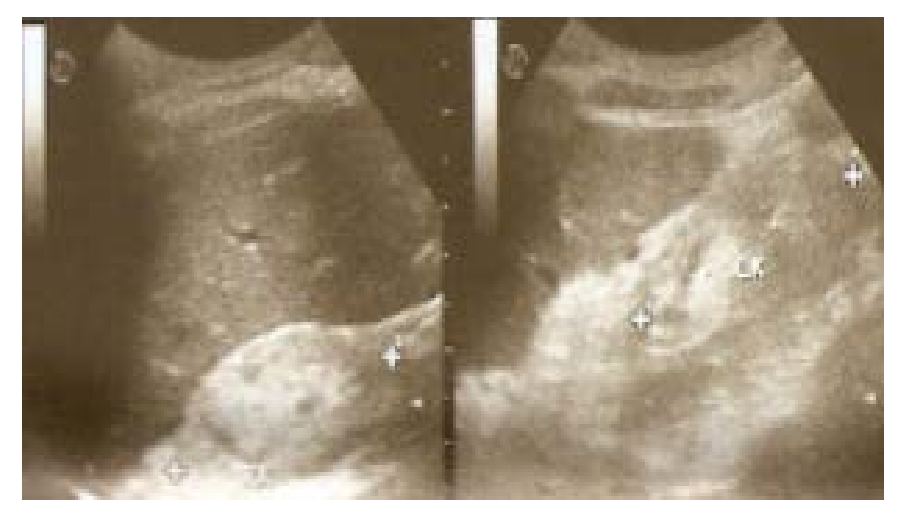

Figure 1. Small hyperechoic kidney with loss of cortico-medullary differentiation in patient with chronic renal failure.

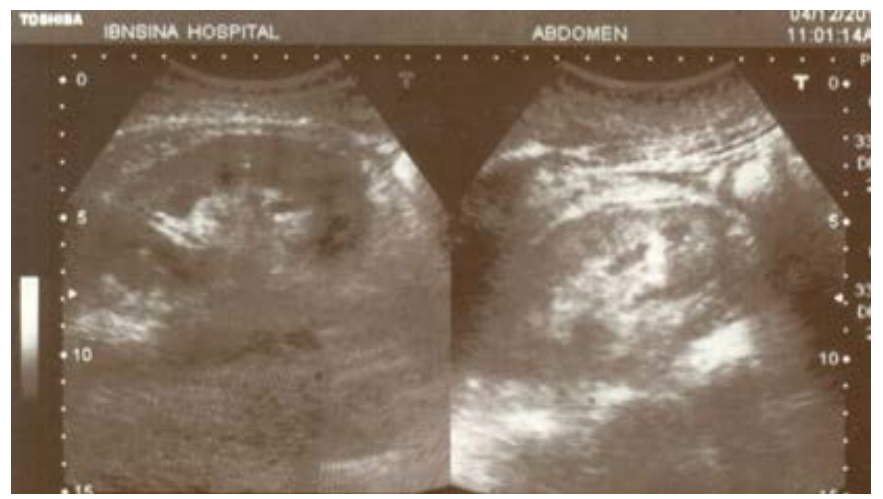

Figure 2. Shows enlarged hypoechoic kidney in acute renal parenchymal disease in a patient with Systemic Lupus Erthromatosus. 


\section{Discussion}

Renal parenchymal diseases are one of the most common health problems that cause severe morbidity and mortality. Ultrasound is an essential imaging method for the evaluation of patients presented with renal diseases especially for end-stage kidney diseases. Correlation with renal biopsy is necessary to confirm the final accurate diagnosis. There were several authors have studied sonographic renal parameters in an attempt to establish their relevance in evaluation of specific renal disease processes [7]. In this study, 204 patients with confirmed renal parenchymal disease were examined. It was observed that $39.81 \%$ of the patients had no clear history. The disease progresses silently until the symptoms appear. In this study diabetes and hypertension were the most common causes of renal parenchymal diseases. Hypertension is strongly related to renal parenchymal diseases. Most primary renal diseases alterelectrolytes balance and volume control and this may cause clinical hypertension. Preston et al. concluded that renal parenchymal diseases were common causes of hypertension. Chronic kidney disease and systemic hypertension were interrelated. However persistent hypertension is an essential cause of chronic renal disease while renal parenchymal diseases were common causes of secondary hypertension [8]. In our study we found that hypertension was the most common finding (68\%) in the study sample and this was attributed to the renal parenchymal diseases. The present study showed that diabetes is the second cause of renal parenchymal disease. This finding is consistent with a study performed on diabetic nephropathy which reported that, diabetes mellitus (type 1 and 2) affect the renal function such as glomerular filtration and renal volume. Kidney volume is reduced in the late stage. Diabetes also influences renal vascularity and alter Doppler indices such as resistive index (RI) values [9].

The sonographic findings of the kidneys had been evaluated in the present study. The sonographic evaluation provides accurate and precise values (high positive predictive values) for assessing renal parenchymal disease [10]. In our study, we found that the echogenicity of renal parenchyma and cortex were both equally and grossly increased in acute, chronic and end-stage parenchymal diseases. Increased echogenicity of renal cortex has proven to be significantly related to various parenchymal pathological changes such as tubular atrophy, fluid retention, arteriosclerosis and hyaline cylinders [11] [12]. Fiegler et al. [13] reported that the echogenicity of the renal parenchyma was correlated with glomerular and interstitial findings. There was a significant correlation between echogenicity of the renal parenchyma and prolonged pathological processes of the renal parenchyma. This result was consistent with our study which revealed that renal cortex and parenchyma were both hyperechoic. Therefore, echogenicity is a necessary sonographic parameter which is capable of classifying and progression of the parenchymal diseases.

\section{Conclusion}

The ultrasound plays a great role in evaluation of renal parenchymal diseases. It is capable to differentiate renal parenchymal diseases and this enables their follow-up and facilitates the choice of appropriate medication and treatment.

\section{References}

[1] Radermacher, J. Ultrasonography of the Kidney and the Renal Vessels Part I: Normal Findings, Inherited and Renoparenchymatous Diseases. Dept. of Nephrology, Klinikum Minden. http://handsonecho.com/sites/53072f21c97d797504000002/content_entry530f

[2] Brant, W. (2001) Ultrasound. Lippincott, Williams and Willkins, Philadelphia.

[3] Bates, J.A. (2010) Abdominal Ultrasound, How, Why and When. 2nd Edition, Churchill Livingstone, 155.

[4] Emamian, S.A., Nielson, M.B., Pedersen, J.F. and Ytte, L. (1993) Kidney Dimensions at Sonography: Correlation with Age, Sex, and Habitus in 665 Adult Volunteers. AJR, 160, 83-88. http://www.ajronline.org/doi/abs/10.2214/ajr.160.1.8416654

[5] Jones, T.B., Riddick, L.R., Harpen, M.D., Dubuisson, R.L. and Samuels, D. (1983) Ultrasonographic Determination of Renal Mass and Renal Volume. Journal of Ultrasound in Medicine, 2, 151-154. http://www.researchgate.net/publication/16343740_Ultrasonographic_determination

[6] Smith, M.C. and, Dunn, M.J. (1995) Hypertension in Renal Parenchymal Disease. In: Laragh, J.H. and Brenner, B.M., Eds., Hypertension: Pathophysiology, Diagnosis and Management, Raven Press, New York, 2081-2102.

[7] Brown, P. (2003) Ultrasond in Diffuse Renal Disease. British Medical Ultrasound Society Bulletin, 11, 30-35. http://ult.sagepub.com/content/11/4/30.full.pdf 
[8] Preston, R.A., Singer, I. and Epstein, M. (1996) Renal Parenchymal Hypertension: Current Concepts of Pathogenesis and Management. Archives of Internal Medicine, 156, 602-611.

http://archinte.jamanetwork.com/article.aspx?articleid=621727

http://dx.doi.org/10.1001/archinte.1996.00440060016002

[9] Derchi, L.E., Martinoli, C., Saffioti, S., Pontremoli, R., De Micheli, A. and Bordone, C. (1994) US Imaging and Doppler Analysis of Renal Changes in Non-Insulin-Dependent Diabetes Mellitus. Academic Radiology, 1, 100-105. http://dx.doi.org/10.1016/S1076-6332(05)80826-8

[10] Page, J.E., Morgan, S.H., Eastwood, J.B., Smith, S.A., Webb, D.J., Dilly, S.A., Chow, J., Pottier, A. and Josepha, A.E.A. (1994) Ultrasound Findings in Renal Parenchymal Disease: Comparison with Histological Appearances. Clinical Radiology, 49, 867-870.

[11] Mostbeck, G.H., Kain, R., Mallek, R., Derfler, K., Walter, R., Havelec, L., et al. (1991) Duplex Doppler Sonography in Renal Parenchymal Disease. Histopathologic Correlation. Journal of Ultrasound in Medicine, 10, 189-194. http://link.springer.com/chapter/10.1007\%2F978-3-642-78697-6_11

[12] Rosenfield, A.T. and, Siegel, N.J. (1981) Renal Parenchymal Disease: Histopathologic-Sonographic Correlation. American Journal of Roentgenology, 137, 793-798. http://dx.doi.org/10.2214/ajr.137.4.793

[13] Fiegler, W., Cromme, R., Szekessy, T. and Kampf, D. (1981) Ultrasound in Diffuse Renal Parenchymal Disease. Rofo, 135, 645-648. http://www.ncbi.nlm.nih.gov/pubmed/6212379 